\section{Early traits of metabolic syndrome in pediatric post-cancer survivors: outcomes in adolescents and young adults treated for childhood medulloblastoma}

\author{
Fatores precoces para síndrome metabólica em sobreviventes \\ de câncer pediátrico: resultados em adolescentes e adultos \\ jovens tratados por meduloblastoma na infância
}

Adriana Aparecida Siviero-Miachon', Carlos Manoel de Castro Monteiro², Liliane Viana Pires ${ }^{3}$, Ana Carolina Rozalem4, Nasjla Saba da Silva ${ }^{4}$, Antonio Sergio Petrilli' ${ }^{4}$ Angela Maria Spinola-Castro'

\begin{abstract}
Objective: To analyze traits of metabolic syndrome (MetS) in medulloblastoma survivors. Subjects and methods: Sixteen childhood medulloblastoma survivors aged 18.0 (4.4) years, with history of craniospinal radiation therapy (RT) were compared with nine control subjects matched by age, gender, and body mass index, according to fat distribution, metabolic and cardiovascular variables. Results: Medulloblastoma patients showed increases in waist circumference and its relationships (all $p<0.05$ ), and HOMA1-IR $(p=0.006)$, which were modified by growth hormone $(\mathrm{GH})$ secretion status. However, these increases were within normal range. Conclusions: Adolescent and young adult survivors of medulloblastoma showed centripetal fat deposition and decreased insulin sensitivity, associated with GH status. Pediatric brain tumor survivors following RT should be monitored for the diagnosis of MetS traits predisposing to cardiovascular disease. Arq Bras Endocrinol Metab. 2011;55(8):653-60
\end{abstract}

\section{Keywords}

Medulloblastoma/therapy; medulloblastoma/drug therapy; medulloblastoma/radiotherapy; medulloblastoma/prevention and control; cardiovascular diseases; metabolic syndrome $\mathrm{X}$

\section{RESUMO}

Objetivo: Analisar características que predispõem para síndrome metabólica (SM) em sobreviventes de meduloblastoma. Sujeitos e métodos: Dezesseis sobreviventes de meduloblastoma pediátrico, 18,0 $(4,4)$ anos, história de radioterapia (RT) cranioespinhal, comparados a nove controles pareados por idade, sexo e índice de massa corporal, de acordo com distribuição de gordura, variáveis metabólicas e cardiovasculares. Resultados: Pacientes com meduloblastoma mostraram aumento da cintura e relações (todos $p<0,05)$ e HOMA1-IR $(p=0,006$ ), modificados pela secreção do hormônio de crescimento $(\mathrm{GH})$, mas dentro dos limites de normalidade. Conclusões: Sobreviventes adolescentes e adultos jovens de meduloblastoma apresentaram deposição centrípeta de gordura e diminuição da sensibilidade à insulina, associados ao estado do GH. Sobreviventes de tumor cerebral pediátrico que receberam RT devem ser monitorados para diagnosticar fatores para SM predispondo à doença cardiovascular. Arq Bras Endocrinol Metab. 2011;55(8):653-60

\section{Descritores}

Meduloblastoma/terapia; meduloblastoma/quimioterapia; meduloblastoma/radioterapia; medulolastoma/prevenção e controle; doenças cardiovasculares; síndrome X metabólica
Division of Pediatric Endocrinology, Department of Pediatrics, Escola Paulista de Medicina, Universidade Federal de São Paulo (Unifesp/ EPM), São Paulo, SP, Brazil ${ }^{2}$ Division of Cardiology, Department of Medicine, Unifesp/ EPM, São Paulo, SP, Brazil

${ }_{3}$ Pharmaceutical Science School, Department of Food Science and Experimental Nutrition, Universidade de São Paulo (USP), São Paulo, SP, Brazi ${ }^{4}$ Pediatric Oncology Institute, IOP/ GRAACC, Department of Pediatrics, Unifesp/EPM, São Paulo, SP, Brazil

Correspondence to Angela Maria Spinola-Castro Rua Doutor Diogo de Faria, 307 04037-000 - São Paulo, SP, Brazil aspinola.dped@epm.br

Received on 21/Sept/2011 Accepted on 16/Oct/2011 


\section{INTRODUCTION}

$\mathrm{M}$ edulloblastoma is one of the most common childhood brain malignancies, accounting for approximately $10 \%-20 \%$ of pediatric brain tumors. Pediatric tumor types are more sensitive to chemotherapy (CT) and to adjuvant radiation therapy (RT), compared with adults, and often require high doses of craniospinal RT, due to their propensity to disseminate within the neuraxis (1). Consequently, along with the better care provided to pediatric medulloblastoma, the spectrum of side effects is broader: RT, particularly when combined with CT, brings increased risk of severe long-term after-effects involving neurologic, cognitive, as well as endocrine and metabolic functions $(2-5)$. In contrast to other types of tumors, especially those of the sellar region (e.g. craniopharyngioma), the resulting endocrine and metabolic derangements in medulloblastoma are exclusively secondary to therapy damage.

Post-pediatric cancer survivors, including brain tumors, may develop MetS traits due to hormonal deficiencies, particularly growth hormone $(\mathrm{GH})$ deficiency, drug or RT damage, endothelial impairment, physical inactivity, and/or adipose tissue dysfunction, but this issue has not been elucidated yet (6-13). Cranial RT and its consequent hypothalamic dysfunction is one of the predisposing mechanisms involved in premature cardiovascular disease (CVD), frequently described in survivors of pediatric cancers (6). According to a statement developed by the American Heart Association along with the Council for Cardiovascular Disease in the Young, post-pediatric cancer survivors may present increase epidemiological evidence of manifesting CVD early in adult life, usually after 30 years of age (6-8).

To date, studies that focused on metabolic derangements in childhood medulloblastoma survivors are scarce because, despite the advances in therapy regimens, the relapse rate within five years after therapy withdrawal is still high. Additionally, previous reports included medulloblastoma among other types of pediatric brain tumors with cranial RT $(6-8,11$ $12)$. Thus, the purpose of this study was to differentiate MetS traits in adolescents and young adult survivors of childhood medulloblastoma who were followed up in a single center. In addition, it was evaluated whether these features were modified by GH status.

\section{METHODS}

\section{Study population}

This cross-sectional study was carried out on a sample of male and female medulloblastoma survivors admitted for treatment at the Pediatric Oncology Institute, Universidade Federal de São Paulo - Unifesp/EPM, São Paulo, Brazil, from February 1990 to August 2005, and in normal healthy controls. The study was approved by the Ethical Research Committee of Unifesp/ EPM, in accordance with the Declaration of Helsinki (project no. 1867/06 - Unifesp/EPM). Patients or parents, when appropriate, signed an informed consent form that allowed participation in this study.

Medulloblastoma survivors fully completed therapy regimens, which encompassed total or partial surgical resection, CT, craniospinal RT (24 Gy), and radiotherapy boost ( $54 \mathrm{~Gy}$ ). CT was delineated with a combination of standard drugs comprising: carboplatin, vincristine, ifosfamide, veposide, cisplatin, cyclophosphamide, and temozolomide (2-4). Characteristics of host/disease and therapy were assessed from medical records and included patient age at diagnosis, time since therapy withdrawal, hormonal deficiencies, and therapy employed. All medulloblastoma subjects were previously evaluated in relation to $\mathrm{GH}$ secretion status (insulin tolerance test, ITT), and GH peak $(9,10)$. They were then stratified into two groups for comparison: GH-deficient (GHD) and the Non-GHD medulloblastoma survivors, whose GH peak was, respectively, lower than or equal to $5 \mu \mathrm{g} / \mathrm{L}$, or over $5 \mu \mathrm{g} / \mathrm{L}$. Medulloblastoma survivors presented complete clinical remission (complete or subtotal resection, but no evidence of cerebrospinal fluid dissemination), completed the treatment protocol, and were off therapy for at least two years since diagnosis. Survivors and controls were both included in this assessment if they met the following criteria: chronological age of 12 years or older; renal, thyroid, gonadal and adrenal profiles within the normal range (spontaneous or under appropriate hormonal replacement therapy). Exclusion criteria were the following therapies and conditions: use of anorexigens, insulin-lowering medications or other drugs interfering with adiposity (e.g. metformin, sibutramine, and fluoxetine); exogenous human recombinant growth hormone (rhGH) administration two years before study enrollment; and bone marrow transplantation. The control group presented no past medical history, was matched to the medulloblastoma group based on age, gender and body mass 
index (BMI), and was randomly recruited among medical students from the Unifesp/EPM.

\section{Measurements}

The following variables were transversally evaluated in both medulloblastoma survivors and controls:

Systolic and diastolic blood pressure: supine systolic and diastolic blood pressure (BP) was measured in the right arm using a manual sphygmomanometer $\left(\right.$ Tycos $\left.{ }^{\circledR}\right)$, and the mean of three measurements, after a five-minute rest period, was used. Hypertension was defined according to BP cutoff points, as follows: systolic BP equal or higher than $130 \mathrm{mmHg}$, and/or diastolic BP equal or higher than $85 \mathrm{mmHg}$, or use of antihypertensive drug (patients 18 years of age or older) $(14,15)$, or systolic and/or diastolic BP equal or higher than the $95^{\text {th }}$ percentile for adolescents (16).

Anthropometric variables and body composition: weight and height were analyzed as $\mathrm{Z}$-scores $(\mathrm{Z}$ weight and $Z$ height, respectively) $(17,18)$. Final adult height was defined as growth speed lower than $1.0 \mathrm{~cm}$ per year; bone age equal or greater than 14.5 years in girls and 16.5 in boys; being fully pubertal, as defined by Tanner stage 5 or greater, in boys; and having spontaneous menarche, in girls $(19,20)$. Regarding BMI, which was calculated as weight divided by height in meters squared $\left(\mathrm{kg} / \mathrm{m}^{2}\right)$, and analyzed as Z-scores, obesity was defined as BMI Z-score $(\mathrm{Z} \mathrm{BMI})>2.0$ standard deviation (SD) $(17,18)$.

Total body fat (in percentage, \%), lean body mass (in $\mathrm{kg}$ ) and body water (in \%) were assessed by means of electrical bioimpedance (Model 310 Biodynamics $^{\circledR}$ ), with patients in supine position, arms and legs away from the body. After asepsis of the skin, two electrodes were positioned distally and proximally in the right foot and hand. The mean of three measurements was used in the analysis. Total body fat above the $95^{\text {th }}$ percentile was defined as obesity in patients younger than 18 years of age (21), and cutoff values based on the National Health and Evaluation Survey (NHANES) were used for patients 18 years old or older $(35.2 \%$ and $30.3 \%$ for females and males, respectively) (22).

Fat distribution: the following circumferences were determined: waist circumference (WC, in $\mathrm{cm}$ ), hip circumference $(\mathrm{HC}$, in $\mathrm{cm})$, and their relationships: waist-to-hip ratio, and waist-to-height ratio. WC and HC were measured according to the method described elsewhere (23). Regarding WC, the following cutoff values were considered for adults: males greater than $102 \mathrm{~cm}$ and females greater than $88 \mathrm{~cm}$ (older than 19 years of age), based on the National Cholesterol Education Program - Adult Treatment Panel III (NCEP-ATP III) (14); males $94 \mathrm{~cm}$ or greater and females $80 \mathrm{~cm}$ or greater (older than 16 years of age), according to the International Diabetes Federation (IDF) (15). Cutoff values were modified for adolescents as follows: WC equal or greater than the $90^{\text {th }}$ percentile (19 years of age or older), according to NCEP-ATP III (Cook and cols. study) (24), and WC greater than the $90^{\text {th }}$ percentile ( 16 years of age or younger) according to the IDF (25). Data from the Bogalusa Study (26) by Freedman and cols. (1999), was employed for WC percentiles. A waist-to-height ratio above 0.5 indicated visceral adiposity (27).

\section{Metabolic profile}

Lipid panel: total cholesterol, high-density lipoprotein (HDL) cholesterol, and triglycerides were determined using a colorimetric enzymatic method. Low-density lipoprotein (LDL) cholesterol was calculated by the formula described by Friedewald and cols. (1972) (28). In relation to HDL cholesterol and triglycerides, the cutoff values proposed by NCEP-ATP III and Cook and cols. $(14,24)$, and the IDF $(15,25)$ were considered to define dyslipidemia. As for HDL cholesterol levels, according to both criteria for adult patients $(14,15)$, the cutoff values were below $1.0 \mathrm{mmol} / \mathrm{L}$ (males), and below $1.3 \mathrm{mmol} / \mathrm{L}$ (females). For adolescents, the cutoff values were equal or lower than $1.0 \mathrm{mmol} / \mathrm{L}$ (Cook and cols. study) (24), and lower than $1.0 \mathrm{mmol} / \mathrm{L}$ (IDF) (25), for both genders. As for triglyceride levels, according to NCEP-ATP III (14) and the IDF (15), cutoff values were equal or greater than $1.7 \mathrm{mmol} / \mathrm{L}$ for adult patients (both genders). For adolescents, the cutoff values were equal or greater than $1.2 \mathrm{mmol} / \mathrm{L}$ (Cook and cols. study) (24), and equal or greater than $1.7 \mathrm{mmol} / \mathrm{L}$ (IDF) (25), for both genders.

Glucose, insulin and insulin sensitivity: fasting glucose and insulin levels were assessed using an automated method. Altered glycemia was defined according to Genuth and cols. (29) In order to establish insulin sensitivity, glucose and insulin levels were determined to calculate the homeostatic model assessment of insulin resistance (HOMAl-IR) (30). HOMAl-IR above 2.71 (31) or above 3.16 (32) were determined as cutoff levels in adults and adolescents, respectively, to define IR. Hyperinsulinemia was defined as an insulin level above $173.6 \mathrm{pmol} / \mathrm{L}$. 
Insulin-like growth factor-1: insulin-like growth factor-1 (IGF-1) was analyzed by radioimmunoassay after organic solvent extraction and celite column partition chromatography $(33,34)$.

\section{Cardiovascullar markers}

Common carotid artery intima-media thickness: common carotid artery (CCA) intima-media thickness (IMT) was assessed by ultrasound after a mean of three measurements of the posterior wall of the bilateral common carotid, $1 \mathrm{~cm}$ away from the carotid bifurcation, while patients were in supine position and at rest (Toshiba Powervision ${ }^{\circledR}$ with 7-10 MHz vascular linear transducer) (33).

Two-dimensional Doppler echocardiogram: heart dimensions and variables related to systolic and diastolic function were assessed (Philips EnVisor ${ }^{\circledR}$ version C.1.3, with 2.5-3.5 MHz multifrequency transducer). Heart dimensions comprised left ventricle (LV) mass (in grams), LV mass index (LV mass corrected for body surface area, in $\mathrm{g} / \mathrm{m}^{2}$ ), and left atrium (LA, in $\mathrm{mm}$ ). LV systolic function variables included ejection fraction $(\mathrm{EF}$, in \%), and percent shortening (PS, in \%); diastolic function variables encompassed mitral valve waves $\mathrm{E} / \mathrm{A}$ ratio, mitral wave E deceleration time (msec), and myocardial performance index (MPI). EF below 55\% and PS below 30\% were considered as altered LV systolic function $(9,33,34)$.

\section{Statistical analysis}

Kolmogorov-Smirnov normality test and Levene test were initially conducted to evaluate data distribution and group variances. Variables with normal distribution and equal variance were presented as means, standard deviations (SD), and 95\% confidence intervals (CI). Variables that presented non-normal distribution and/or unequal variance were transformed into natural logarithm (ln) and were presented as medians and ranges (minimum - maximum). Medulloblastoma and controls were compared with respect to quantitative variables using t test for independent samples. The subpopulation of GHD medulloblastoma subjects was compared with the Non-GHD and normal healthy controls, using one-way analysis of variance (ANOVA) in relation to the quantitative variables described. Pairwise comparison test (Tukey's test) was carried out if ANOVA presented $\mathrm{p}<0.05$. Fisher's exact test was used to evaluate the association between prevalence of obesity (as total body fat), centripetal obesity (circumferences and relationships), dyslipidemia (HDL cholesterol and triglycerides cutoff values), IR (as HOMAl-IR cutoff values), and disease/therapy. Alpha level was set at 0.05 . Statistical analyses were performed using SPSS 13.0 (SPSS, Inc., Chicago, IL).

\section{RESULTS}

\section{Study population}

From the 81 medulloblastoma patients admitted for treatment at the IOP/GRAACC from February 1990 to August 2005, 48/81 (60\%) died or abandoned therapy, and 20/81 (24.7\%) were considered eligible for this study; four of them refused to participate. The study population was made up of 16 medulloblastoma survivors aged [mean (SD)] 18.0 (4.0) years, who were 11.3 (4.5) years old at the time of medulloblastoma diagnosis, $5.9(5.3)$ years after therapy withdrawal. The majority was male $(62.5 \%), 2$ patients were prepubertal, and $68.7 \%$ had reached final adult height. BMI was $21.4(4.2) \mathrm{kg} / \mathrm{m}^{2}$ and Z BMI -0.23 (1.55). The control sample was composed of 9 subjects aged 20.0 (5.1) years, $33.3 \%$ males, all pubertal, $66.7 \%$ had reached final adult height, BMI $21.0(2.5) \mathrm{kg} / \mathrm{m}^{2}$ and $\mathrm{Z}$ BMI -0.29 (1.15) SD, as shown in table 1.

Six of the $16(37.5 \%)$ medulloblastoma subjects were considered GHD; however, only l patient had received recombinant human $\mathrm{GH}(\mathrm{rhGH})$ for a 2 -year period. In addition, $7 / 16(43.7 \%)$ survivors were under levothyroxine sodium replacement therapy, with 4/16 (25\%) showing spinal RT-induced primary hypothyroidism, and $3 / 16(18.7 \%)$ having post-total thyroi-

Table 1. Clinical and anthropometric data of adolescent and young adult survivors of childhood medulloblastoma and normal, healthy controls matched by age, gender, and BMI

\begin{tabular}{lcc}
\hline \multirow{2}{*}{ Variables } & \multicolumn{2}{c}{ Group } \\
\cline { 2 - 3 } & $\begin{array}{c}\text { Medulloblastoma } \\
(\mathbf{n}=\mathbf{1 6})\end{array}$ & $\begin{array}{c}\text { Control } \\
(\mathbf{n = 9 )}\end{array}$ \\
\hline Age at assessment (years) & $18.0(4.4)$ & $20.0(5.1)$ \\
Males & $10 / 16(62.5 \%)$ & $3 / 9(33.3 \%)$ \\
Age at medulloblastoma & $11.3(4.5)$ & - \\
diagnosis (years) & & - \\
Time post-treatment (years) & $5.9(5.3)$ & - \\
Final adult height & $11 / 16(68.7 \%)$ & $6 / 9(66.7 \%)$ \\
BMl (kg/m²) & $21.4(4.2)$ & $21.0(2.5)$ \\
BMl (SD) & $-0.23(1.55)$ & $-0.29(1.15)$ \\
\hline
\end{tabular}

Data are presented as means (SD) or frequencies. BMI: body mass index, SD: standard deviation. 
dectomy secondary to thyroid nodule ( 2 patients diagnosed with colloid goiter and 1 patient with thyroid papillary carcinoma). Three of the 16 (18.7\%) patients (all females) required hormonal replacement therapy due to therapy-induced primary gonadal failure.

Body composition, fat distribution and insulin sensitivity: WC, waist-to-hip ratio and waist-to-height ratio were statistically higher in medulloblastoma patients compared with controls (Table 2). There was a trend toward elevation of total body fat in medulloblastoma subjects; however, no subject was considered obese in BMI analysis.

Medulloblastoma patients presented higher glucose, insulin and HOMAl-IR when compared with controls (Table 3); nonetheless, no patient was glucose-intolerant or presented with hyperinsulinemia. Three of the $16(18.7 \%)$ medulloblastoma subjects presented IR. However, there was no association between obesity, centripetal obesity, IR and disease/therapy.

Table 2. Blood pressure, anthropometric, body composition and fat distribution variables in adolescent and young adult survivors of medulloblastoma, compared with normal healthy controls ( $\left.{ }^{*} p<0.05\right)$

\begin{tabular}{|c|c|c|c|}
\hline Variables & $\begin{array}{l}\text { Medulloblastoma } \\
\qquad(\mathrm{n}=16)\end{array}$ & $\begin{array}{l}\text { Control } \\
(n=9)\end{array}$ & $\begin{array}{c}\text { [95\% Cl } \\
\text { of the } \\
\text { difference] } \\
\text { p value }\end{array}$ \\
\hline Systolic BP (mmHg) & $108.4(14.4)$ & $106.7(8.7)$ & $\begin{array}{c}{[-9.2 ; 12.7]} \\
0.752\end{array}$ \\
\hline Diastolic BP (mmHg) & $61.6(56.6-80)$ & $60.3(58.6-76.7)$ & $\begin{array}{c}- \\
0.634\end{array}$ \\
\hline Weight Z-score (SD) & $-0.86(1.42)$ & $-0.44(1.10)$ & $\begin{array}{c}{[-1.56 ; 0.70]} \\
0.449\end{array}$ \\
\hline Height Z-score (SD) & $-1.28(1.19)$ & $-0.87(1.34)$ & $\begin{array}{c}{[-1.49 ; 0.66]} \\
0.432\end{array}$ \\
\hline Total body fat (\%) & $22.3(10.8)$ & $14.9(9.0)$ & $\begin{array}{c}{[-1.3 ; 16.2]} \\
0.093\end{array}$ \\
\hline Lean body mass (kg) & $41.6(13.2)$ & $39.8(12.3)$ & $\begin{array}{c}{[-9.3 ; 12.9]} \\
0.742\end{array}$ \\
\hline Body water (\%) & $70.9(6.3)$ & $69.2(2.5)$ & $\begin{array}{c}{[-2.8 ; 6.3]} \\
0.441\end{array}$ \\
\hline WC (cm) & $76.8(10.1)$ & $67.9(5.6)$ & $\begin{array}{c}{[1.3 ; 16.6]} \\
0.024^{\star}\end{array}$ \\
\hline $\mathrm{HC}(\mathrm{cm})$ & $90.3(10.1)$ & $92.9(10.2)$ & $\begin{array}{c}{[-11.3 ; 6.2]} \\
0.547\end{array}$ \\
\hline Waist-to-hip ratio & $0.85(0.06)$ & $0.74(0.07)$ & $\begin{array}{c}{[0.05 ; 0.16]} \\
0.001^{*}\end{array}$ \\
\hline Waist-to-height ratio & $0.50(0.40-0.60)$ & $0.40(0.40-0.50)$ & $\begin{array}{c}- \\
0.018^{*}\end{array}$ \\
\hline
\end{tabular}

Values are expressed as means (SD) [95\% $\mathrm{Cl}$ of the difference] or medians (range); $\mathrm{Cl}$ : confidence interval; SD: standard deviation; BP: blood pressure; WC: waist circumference; $\mathrm{HC}$ : hip circumference.
Lipid panel and echocardiographic variables: HDL cholesterol and echocardiographic parameters of systolic function (EF and PS) were decreased in medulloblastoma patients compared with controls (Tables 3 and 4 , respectively). There was no difference in the prevalence of dyslipidemia between medulloblastoma patients and normal healthy controls, using different criteria. No medulloblastoma patient presented alterations in EF.

Growth hormone status effect on quantitative variables: $\mathrm{GH}$ status modified some of the studied outcomes, in the comparison of the three groups: $G H D(\mathrm{n}=$ $6)$, Non-GHD medulloblastoma survivors $(\mathrm{n}=10)$, and controls $(\mathrm{n}=9)$, as follows: $\mathrm{Z}$ height, waist-to-hip and waist-to-height ratios, glucose, HOMAl-IR, and EF (ANOVA, $\mathrm{p}<0.05$ ). After a multiple comparison test, $\mathrm{Z}$ height and EF were decreased in GHD, compared with Non-GHD medulloblastoma survivors. Waist-to-hip and waist-to-height ratios, glucose, and HOMAl-IR were increased in GHD medulloblastoma subjects, compared with controls (Tukey's test, all tests $\mathrm{p}<0.05$ ).

Table 3. Metabolic and vascular variables in adolescent and young adult survivors of medulloblastoma, compared with normal healthy controls ( ${ }^{*} p<0.05$ )

\begin{tabular}{|c|c|c|c|}
\hline Variables & $\begin{array}{l}\text { Medulloblastoma } \\
\qquad(n=16)\end{array}$ & $\begin{array}{l}\text { Control } \\
(\mathrm{n}=9)\end{array}$ & $\begin{array}{c}\text { [95\% Cl } \\
\text { of the } \\
\text { difference] } \\
\text { t test } \\
p \text { value }\end{array}$ \\
\hline $\begin{array}{l}\text { Total cholesterol } \\
(\mathrm{mmol} / \mathrm{L})\end{array}$ & $4.4(0.9)$ & $4.0(1.6)$ & $\begin{array}{c}{[-0.7 ; 1.4]} \\
0.465\end{array}$ \\
\hline $\begin{array}{l}\text { LDL cholesterol } \\
(\mathrm{mmol} / \mathrm{L})\end{array}$ & $2.6(0.7)$ & $2.3(0.6)$ & $\begin{array}{c}{[-0.3 ; 0.8]} \\
0.357\end{array}$ \\
\hline $\begin{array}{l}\text { HDL cholesterol } \\
(\mathrm{mmol} / \mathrm{L})\end{array}$ & $1.3(0.4)$ & $1.6(0.2)$ & $\begin{array}{c}{[-0.5 ; 0.0]} \\
0.053\end{array}$ \\
\hline $\begin{array}{l}\text { Triglycerides } \\
(\mathrm{mmol} / \mathrm{L})\end{array}$ & $1.0(0.7)$ & $0.9(0.5)$ & $\begin{array}{c}{[-0.5 ; 0.6]} \\
0.874\end{array}$ \\
\hline IGF-1 (nmol/L) & $34.8(17.0)$ & $32.3(8.6)$ & $\begin{array}{c}{[-10.1 ; 15.2]} \\
0.682\end{array}$ \\
\hline Glucose (mmol/L) & $4.9(0.5)$ & $4.5(0.4)$ & $\begin{array}{c}{[0.0 ; 0.8]} \\
0.045^{\star}\end{array}$ \\
\hline Insulin (pmol/L) & $40.3(13.9-121.5)$ & $17.4(13.9-27.0)$ & $\begin{array}{c}- \\
0.002^{*}\end{array}$ \\
\hline HOMA1-IR & $1.15(0.40-3.80)$ & $0.40(0.40-0.90)$ & - \\
\hline Right CCA IMT (mm) & $0.65(0.09)$ & $0.61(0.05)$ & $\begin{array}{c}{[-0.02 ; 0.12]} \\
0.191\end{array}$ \\
\hline Left CCA IMT (mm) & $0.65(0.51-0.84)$ & $0.63(0.51-0.65)$ & $\begin{array}{c}- \\
0.426\end{array}$ \\
\hline
\end{tabular}

Values are expressed as means (SD) [95\% Cl of the difference] or medians (range); $\mathrm{Cl}$ : confidence interval; SD: standard deviation; LDL: Iow density lipoprotein, HDL: high density lipoprotein; IGF-1: insulin-like growth factor-1; HOMA1-IR: homeostasis model assessmentinsulin resistance; CCA: common carotid artery; IMT: intima-media thickness. 
Table 4. Echocardiographic variables in adolescent and young adult survivors of medulloblastoma, compared with normal healthy controls ( ${ }^{*} p$ $<0.05)$

\begin{tabular}{|c|c|c|c|}
\hline Variables & $\begin{array}{l}\text { Medulloblastoma } \\
\quad(n=16)\end{array}$ & $\begin{array}{l}\text { Control } \\
(n=9)\end{array}$ & $\begin{array}{c}\text { [95\% Cl } \\
\text { of the } \\
\text { difference] } \\
p \text { value in } \\
\text { t test }\end{array}$ \\
\hline LV mass (g) & $85.1(28.1)$ & $91.5(19.9)$ & $\begin{array}{c}{[-28.4 ; 15.6]} \\
0.553\end{array}$ \\
\hline LV mass index $\left(\mathrm{g} / \mathrm{m}^{2}\right)$ & $55.7(12.7)$ & $59.8(8.1)$ & $\begin{array}{c}{[-13.9 ; 5.7]} \\
0.394\end{array}$ \\
\hline $\mathrm{LA}(\mathrm{mm})$ & $28.6(3.2)$ & $30.2(2.6)$ & $\begin{array}{c}{[-4.2 ; 1.0]} \\
0.216\end{array}$ \\
\hline $\begin{array}{l}\text { Ejection fraction } \\
(\%)\end{array}$ & $67.8(4.2)$ & $72.3(6.4)$ & $\begin{array}{c}{[-8.9 ;-0.1]} \\
0.043^{\star}\end{array}$ \\
\hline $\begin{array}{l}\text { Percent shortening } \\
(\%)\end{array}$ & $34.0(4.3)$ & $37.7(3.8)$ & $\begin{array}{c}{[-7.1 ;-0.02]} \\
0.049^{\star}\end{array}$ \\
\hline $\begin{array}{l}\text { Mitral valve waves } \\
\text { E:A ratio }\end{array}$ & $1.76(0.28)$ & $1.70(0.31)$ & $\begin{array}{c}{[-0.20 ; 0.32]} \\
0.626\end{array}$ \\
\hline $\begin{array}{l}\text { Mitral wave } \mathrm{E} \\
\text { deceleration time } \\
\text { (msec) }\end{array}$ & $180.9(37.4)$ & $197.2(25.4)$ & $\begin{array}{c}{[-46.9 ; 14.2]} \\
0.279\end{array}$ \\
\hline $\begin{array}{l}\text { Myocardial } \\
\text { performance index }\end{array}$ & $44.0(20.0-87.0)$ & $39.0(30.0-53.0)$ & $\begin{array}{c}- \\
0.556\end{array}$ \\
\hline
\end{tabular}

Values are expressed as means (SD) [95\% $\mathrm{Cl}$ of the difference] or medians (range); $\mathrm{Cl}$ : confidence interval; SD: standard deviation; LV: left ventricle; LA: left atrium.

\section{DISCUSSION}

This study investigated whether adolescent and young adult survivors of medulloblastoma already present MetS traits. The major finding of this study was that some MetS traits, such as centripetal fat deposition, altered lipid profile and decreased insulin sensitivity, were detected, at a young age, in childhood medulloblastoma survivors with history of craniospinal RT, compared with normal healthy controls, even though within normal limits so far. Additionally, GH status influenced fat distribution variables, and insulin sensitivity was also observed.

Adiposity, possibly by means of hyperinsulinism and IGF- 1 , has a role in promoting carcinogenesis and, in its turn, carcinogenesis could also contribute to the development of MetS in survivors of various malignancies $(6,35)$. In this study, body composition was evaluated by electrical bioimpedance, and fat distribution by circumferences and their relationships, which are not the gold standard methods to date. Nevertheless, total body fat showed a trend toward increase, and WC ratios were all increased (particularly in the GHD subpopulation) in medulloblastoma patients, which is in accordance with previous studies (11), even though this increase was within normal limits. Waist-to-height ratio is the index that better reflects centripetal deposition of fat (27) and has a strong correlation with visceral fat evaluated by magnetic resonance imaging, which is the gold standard (36). However, we must emphasize that waist-to-height ratio should be carefully interpreted in this sample, since GHD medulloblastoma subjects presented decreased $\mathrm{Z}$ height, as a consequence of spinal RT. Hypothalamic lesion (and GH deficiency) secondary to craniospinal RT could possibly be one of the main causes of alterations in body fat compartments and decreased height in patients treated for medulloblastoma $(3,4,6,8)$. That is the reason why current regimens are proposing low doses of craniospinal RT ( 18 Gy) to treat nondisseminated medulloblastoma, despite the aggressiveness of the disease, in order to diminish endocrine after-effects $(37,38)$. These kind of studies are scarce and analyze medulloblastoma together with other malignancies. Notwithstanding, the risk of central obesity in survivors of childhood cancer, including acute lymphocytic leukemia, craniopharyngioma, following bone marrow transplantation (BMT), and brain tumors with cranial RT history, has already been described and concurs with the present study (6-13).

IR is the factor that links all other MetS criteria, together with endothelial dysfunction $(6,8,36)$. In this study, medulloblastoma survivors showed increased insulin secretion, decreased insulin sensitivity, and an unfavorable lipid profile. However, to date, these variations are within normal values. Hyperinsulinemia and an adverse lipid profile have been described as an effect of therapy in patients treated for various types of cancer with adjuvant RT, and after BMT $(6,8-11,39)$. In addition, GH status was associated with insulin sensitivity in this sample.

In relation to CCA IMT, which reflects premature asymptomatic atherosclerosis, there was no difference between medulloblastoma patients and controls in this study, and no association with GH status. On the other hand, previous studies have described increased IMT in brain tumor survivors and non-oncologic GHD children and adolescents $(11,33)$. Furthermore, it is known that IMT is positively correlated with RT dosage, and negatively correlated with IGF-1 levels which, in turn, reflect GH secretion status $(6,33,34,40)$. In the present study, the young age of the sample might explain the lack of difference between the groups, ever since all medulloblastoma patients received high doses of cranial RT (54 Gy). Echocardiographic evaluation showed de- 
creased systolic function in medulloblastoma subjects, and an effect of $\mathrm{GH}$, but without clinical relevance. $\mathrm{GH}$ is important for cardiac function and contractility, and CT (particularly with anthracyclines) may impair this function $(8,9,12)$.

The population studied in the present evaluation was made up of only 16 medulloblastoma survivors, who were off therapy for at least 2 years from diagnosis, all treated with CT and craniospinal RT. The small size of the sample is due to the fact that medulloblasto$\mathrm{ma}$ is an extremely aggressive, highly recurrent tumor, limiting the population to be studied (1-5). Nonetheless, they were compared with matched controls, and some differences related to fat distribution and metabolic derangements were evidenced. Although it was not the aim of this study, some other factors, rather than chronological age, could explain the absence of some abnormalities in this subgroup of patients, such as shorter post-treatment interval, overprotection, extreme parental health care, and medical support (6).

In conclusion, patients treated for childhood medulloblastoma at a mean age of 18 years, 5.9 years off therapy presented centripetal adiposity, and decreased insulin sensitivity, all outcomes modified by GH deficiency. No signs of asymptomatic atherosclerosis were detected; however, there were alterations in systolic function variables. Medulloblastoma survivors should be followed up for early diagnosis of metabolic abnormalities, in a way to prioritize interventions and reduce the occurrence of CVD between 30-40 years of age, in this population.

Acknowledgements: the authors would like to thank Maria Verônica Câmara Santos, M.D., for performing the echocardiographic assessments. This report was presented in part at the XX Annual Meeting of the Latin American Society of Pediatric Endocrinology (SLEP), held in Lima (Peru) in October 2008. The study was supported by grants of scientific initiation from National Council for Research and Development, PIBIC/CNPq (to A.C.R.).

Disclosure: no potential conflict of interest relevant to this article was reported.

\section{REFERENCES}

1. Kaderali Z, Lamberti-Pasculli M, Rutka JT. The changing epidemiology of paediatric brain tumours: a review from the Hospital for Sick Children. Childs Nerv Syst. 2009;25(7):787-93.

2. Packer RJ, Cogen P, Vezina G, Rorke LB. Medulloblastoma: clinical and biologic aspects. Neuro Oncol. 1999;1(3):232-50.

3. Merchant TE, Pollack IF, Loeffler JS. Brain tumors across the age spectrum: biology, therapy, and late effects. Semin Radiat Oncol. 2010;20(1):58-66.
4. Saran FH, Driever PH, Thilmann C, Mose S, Wilson P, Sharpe G, et al. Survival of very young children with medulloblastoma (primitive neuroectodermal tumor of the posterior fossa) treated with craniospinal irradiation. Int J Radiat Oncol Biol Phys. 1998;42(5):959-67.

5. Edelstein K, Spiegler BJ, Fung S, Panzarella T, Mabbott DJ, Jewitt $\mathrm{N}$, et al. Early aging in adult survivors of childhood medulloblastoma: long-term neurocognitive, functional, and physical outcomes. Neuro Oncol. 2011;13(5):536-45.

6. Siviero-Miachon AA, Spinola-Castro AM, Guerra-Junior G. Detection of metabolic syndrome features among childhood cancer survivors: a target to prevent disease. Vasc Health Risk Manag. 2008;4(4):825-36.

7. Kavey RE, Allada V, Daniels SR, Hayman LL, McCrindle BW, Newburger JW, et al.; American Heart Association Expert Panel on Population and Prevention Science; American Heart Association Council on Cardiovascular Disease in the Young; American Heart Association Council on Epidemiology and Prevention; American Heart Association Council on Nutrition, Physical Activity and Metabolism; American Heart Association Council on High Blood Pressure Research; American Heart Association Council on Cardiovascular Nursing; American Heart Association Council on the Kidney in Heart Disease; Interdisciplinary Working Group on Quality of Care and Outcomes Research. Cardiovascular risk reduction in high-risk pediatric patients: a scientific statement from the American Heart Association Expert Panel on Population and Prevention Science; the Councils on Cardiovascular Disease in the Young, Epidemiology and Prevention, Nutrition, Physical Activity and Metabolism, High Blood Pressure Research, Cardiovascular Nursing, and the Kidney in Heart Disease; and the Interdisciplinary Working Group on Quality of Care and Outcomes Research: endorsed by the American Academy of Pediatrics. Circulation. 2006;114(24):2710-38.

8. Nuver J, Smit AJ, Postma A, Sleijfer DT, Gietema JA. The metabolic syndrome in long-term cancer survivors, an important target for secondary preventive measures. Cancer Treat Rev. 2002;28(4):195-214.

9. Link K, Moëll C, Garwicz S, Cavallin-Ståhl E, Björk J, Thilén U, et al. Growth hormone deficiency predicts cardiovascular risk in young adults treated for acute lymphoblastic leukemia in childhood. J Clin Endocrinol Metab. 2004;89(10):5003-12.

10. Taskinen M, Lipsanen-Nyman M, Tiitinen A, Hovi L, Saarinen-Pihkala UM. Insufficient growth hormone secretion is associated with metabolic syndrome after allogeneic stem cell transplantation in childhood. J Pediatr Hematol/Oncol. 2007;29(8):529-34.

11. Heikens J, Ubbink MC, Van der Pal HPJ, Bakker PJ, Fliers E, Smilde TJ, et al. Long term survivors of childhood brain cancer have an increased risk for cardiovascular disease. Cancer. 2000;88(9):2116-21.

12. Meacham LR, Chow EJ, Ness KK, Kamdar KY, ChenY, YasuiY, et al. Cardiovascular risk factors in adult survivors of pediatric cancer--a report from the childhood cancer survivor study. Cancer Epidemiol Biomarkers Prev. 2010;19(1):170-81.

13. Srinivasan S, Ogle GD, Garnett SP, Briody JN, Lee JW, Cowell CT. Features of the metabolic syndrome after childhood craniopharyngioma. J Clin Endocrinol Metab. 2004;89(1):81-6.

14. Expert Panel on Detection, Evaluation, and Treatment of High Blood Cholesterol in Adults. Executive Summary of The Third Report of the National Cholesterol Education Program (NCEP) Expert Panel on Detection, Evaluation, and Treatment of High Blood Cholesterol in Adults (Adult Treatment Panel III). JAMA. 2001;285(19):2486-97.

15. Alberti KG, Zimmet P, Shaw J. Metabolic syndrome--a new world-wide definition. A Consensus Statement from the International Diabetes Federation. Diabet Med. 2006;23(5):469-80.

16. National High Blood Pressure Education Program Working Group on High Blood Pressure in Children and Adolescents. The fourth 
report on the diagnosis, evaluation, and treatment of high blood pressure in children and adolescents. Pediatrics. 2004;114(2 Suppl 4th Report):555-76.

17. Ogden CL, Carroll MD, Curtin LR, McDowell MA, Tabak CJ, Flegal KM. Prevalence of overweight and obesity in the United States, 1999-2004. JAMA. 2006;295(13):1549-55.

18. Centers for Disease Control and Prevention [homepage on the internet]. Atlanta: National Center for Health Statistics; c20002005 [updated 2010 Sep 9; cited 2011 Aug 30]. 2000 CDC Growth Charts: United States; [about 2 p.]. Available from: http://www. cdc.gov/growthcharts

19. MarshallWA, Tanner JM. Variations in pattern of pubertal changes in girls. Arch Dis Child. 1969;44(235):291-303.

20. Marshall WA, Tanner JM. Variations in the pattern of pubertal changes in boys. Arch Dis Child. 1970;45(239):13-23.

21. McCarthy HD, ColeTJ, FryT, Jebb SA, Prentice AM. Body fat reference curves for children. Int J Obes (Lond). 2006;30(4):598-602.

22. KellyTL, Wilson KE, Heymsfield SB. Dual energy X-Ray absorptiometry body composition reference values from NHANES. PLoS One. 2009;4(9):e7038.

23. Callaway CW, Chumlea WC, Bouchard C, Himes JH, Lohman TG, Martin AD, et al. Circumferences. In: Lohman TG, Roche AF, Martorell R, editors. Anthropometric standardization reference manual. Champaign: Human Kinetics Books; 1988. p. 39-54.

24. Cook S, Weitzman M, Auinger P, Nguyen M, Dietz WH. Prevalence of a metabolic syndrome phenotype in adolescents: findings from the third National Health and Nutrition Examination Survey, 1988-1994. Arch Pediatr Adolesc Med. 2003;157(8):821-7.

25. Zimmet $P$, Alberti KG, Kaufman F, Tajima N, Silink M, Arslanian $\mathrm{S}$, et al.; IDF Consensus Group. The metabolic syndrome in children and adolescents an IDF consensus report. Pediatr Diabetes. 2007;8(5):299-306.

26. Freedman DS, Serdula MK, Srinivasan SR, Berenson GS. Relation of circumferences and skinfold thicknesses to lipid and insulin concentrations in children and adolescents: the Bogalusa Heart Study. Am J Clin Nutr. 1999;69(2):308-17.

27. Neville KA, Cohn RJ, Steinbeck KS, Johnston K, Walker JL. Hyperinsulinemia, impaired glucose tolerance, and diabetes mellitus in survivors of childhood cancer: prevalence and risk factors. J Clin Endocrinol Metab. 2006;91(11):4401-7.

28. Friedewald WT, Levy RI, Fredrickson DS. Estimation of the concentration of low-density lipoprotein cholesterol in plasma, without use of the preparative ultracentrifuge. Clin Chem. 1972;18(6):499-502.

29. Genuth S, Alberti KG, Bennett P, Buse J, Defronzo R, Kahn R, et al.; Expert Committee on the Diagnosis and Classification of Diabetes
Mellitus. Follow-up report on the diagnosis of diabetes mellitus. The Expert Committee on the Diagnosis and Classification of Diabetes Mellitus. Diabetes Care. 2003;26(11):3160-7.

30. Matthews DR, Hosker JP, Rudenski AS, Naylor BA, Treacher DF, Turner RC. Homeostasis model assesssment: insulin resistance and beta-cell function from fasting glucose and insulin concentrations in man. Diabetologia. 1985;28(7):412-9.

31. Geloneze B, Repetto EM, Geloneze SR, Tambascia MA, Ermetice MN. The threshold value for insulin resistance (HOMA-IR) in an admixtured population IR in the Brazilian Metabolic Syndrome Study. Diabetes Res Clin Pract. 2006;72(2):219-20.

32. Keskin M, Kurtoglu S, Kendirci M, Atabek ME, Yazici C. Homeostasis model assessment is more reliable than the fasting glucose/ insulin ratio and quantitative insulin sensitivity check index for assessing insulin resistance among obese children and adolescents. Pediatrics. 2005;115(4):e500-3.

33. Szczepaniska-Kostro J, Tolwinska J, Urban M, Gardziejczyk M, Głowińska B. Cardiac mass and function, carotid artery intima media thickness, homocysteine and lipoprotein levels in children and adolescents with growth hormone deficiency. J Pediatr Endocrinol Metab. 2004;17(10):1405-13.

34. Colao A. The GH/IGF axis and the cardiovascular system: clinical implications. Clin Endocrinol (Oxf). 2008;69(3):347-58.

35. Hsu IR, Kim SP, Kabir M, Bergman RN. Metabolic syndrome, hyperinsulinemia, and cancer. Am J Clin Nutr. 2007;86(3):S867-71.

36. Janiszewski PM, Oeffinger KC, Church TS, Dunn AL, Eshelman DA, Victor RG, et al. Abdominal obesity, liver fat, and muscle composition in survivors of childhood acute lymphoblastic leukemia. J Clin Endocrinol Metab. 2007;92(10):3816-21.

37. Packer RJ, Goldwein J, Nicholson HS, Vezina LG, Allen JC, Ris $M D$, et al. Treatment of children with medulloblastomas with reduced-dose craniospinal radiation therapy and adjuvant chemotherapy: a Children's Cancer Group Study. J Clin Oncol. 1999;17(7):2127-36.

38. Xu W, Janss A, Packer RJ, Phillips P, Goldwein J, Moshang T Jr. Endocrine outcome in children with medulloblastoma treated with $18 \mathrm{~Gy}$ of craniospinal radiation therapy. Neuro Oncol. 2004;6(2):113-8.

39. Iwayama $\mathrm{H}$, Kamijo $\mathrm{T}$, Ueda $\mathrm{N}$. Hyperinsulinemia may promote growth without $\mathrm{GH}$ in children after resection of suprasellar brain tumors. Endocrine. 2011;40(1):130-3.

40. Appelman-Dijkstra NM, Kokshoorn NE, Dekkers OM, Neelis KJ, Biermasz NR, Romijn JA, et al. Pituitary dysfunction in adult patients after cranial radiotherapy: systematic review and meta-analysis. J Clin Endocrinol Metab. 2011;96(8):2330-40. 